\title{
Land Cover Mapping and Change Analysis in Tropical Humid-highlands: Case of Ndakaini Water Reservoir in Central Kenya
}

\author{
Joram Kagombe ${ }^{1}$ Stephen M. Kiama ${ }^{2} \quad$ James Kungu B ${ }^{3}$ \\ 1. Chief Research Scientist, Kenya Forestry Research Institute, Nairobi, Kenya \\ 2.Technology Dissemination and Service Programme, Kenya Forestry Research Institute, Nairobi, Kenya \\ 3. Professor in Kenyatta University, Department of Environmental sciences
}

\begin{abstract}
We successfully used optical remote sensing approach to test the skills of post-classification change detection technique as well as techniques of circumventing the challenges of cloud/cloud-shadow contamination and of working in a data-scarce environment in tropical humid highlands. The aim was to generate an accurate estimate of current land cover distribution map and analyze land-cover change around Ndakaini area in Kenya. Landsat imageries (TM and $\mathrm{ETM}^{+}$) acquired between 1985 and 2011 and corresponding to the study area was selected. Employing bands 3 and 4 of respective Landsat images, thresholding techniques, Boolean and masking operations were implemented in detecting cloud/cloud-shadows and subsequent removal and filling of gaps. In absence of other historical ancillary data about land cover types, a total of 278 points across the study area were captured from Google Earth and used to evaluate the accuracy of each of the generated land cover maps. From the results, cloud/cloud-shadow gaps were reduced immensely (e.g. $90 \%$ for the 1985 image and $82 \%$ for the 2011 image). With regard to quality of classification outputs, the respective land cover/land-use maps of 2000, 2005 and 2010 anniversaries had fairly high level of overall accuracy (64\%,79\% and 68\% respectively) and Kappa statistic ( 0.47 , 0.69 and 0.53 respectively) while classification outputs of 1985 and 1995 yielded slightly lower overall accuracy $(60 \%)$ and Kappa statistic (0.42). Post-classification change involving three land cover classes, tea plantation, forest/woodlot and annual crop fields denoted as others were successfully determined and conclusions based on trend analysis drawn. The satisfactory results of this study imply the usefulness of post-classification change detection method in generating information about land cover dynamics in tropical humid highlands especially when coupled with robust techniques that adequately circumvent the cloud and cloud-shadow problem and scarcity of ancillary data often common in these areas.
\end{abstract}

Keywords: Post-classification change detection, thresholding and Boolean techniques, landcover change, tropical humid-highlands

DOI: $10.7176 / \mathrm{JNSR} / 10-8-03$

Publication date: April $30^{\text {th }} 2020$

\subsection{Introduction}

Land cover change information at different spatial and time-scales is critical in evaluating ecosystem conditions and environmental trends (Alphan et al., 2009). Knowledge about the kind and the rate of change in the use of land resource is essential for proper planning, management and to regulate the use of such resources (Sreenivasulu et al., 2010). The information is also critical in resource economics as land cover change is attributed to dynamics of proximal livelihood options as well as externalities related to economic activities and resources. In Ndakaini for instance, an area adjacent to Aberdare forest in Kenya, the land cover change have been recognized to bear heavy impact on the water resources especially the quantity and quality of water in Ndakaini dam, being associated with observed dam-siltation coupled with growing uncertainty in water supply in the future as well as ever rising treatment cost borne by Nairobi Water and Sanitation Company. The reservoir, with filled capacity volume of about 70 million cubic meters, supplies $80 \%$ of domestic water to residence of Nairobi city. The reservoir was constructed between 1989 and 1994, replacing previous agricultural related land uses and has since then affected the land use and land cover in the area, which in return affects the water flow and quality.

Indeed, as noted by Sreenivasulu et al. (2010) and Mas (1999), land use change has direct bearing on various hydrological phenomena such as interception, infiltration, surface flow, evaporation with related problems including rainfall-runoff modeling and sedimentation, being well understood if information on land use/land-cover change is available for respective catchment. Thus, as underscored by Alphan et al. (2009), better understanding of these impacts would allow accurate estimation, modeling and forecasting of such dynamics from local to regional levels.

Remote sensing offers a cost-effective alternative of mapping landscape resources and analyzing changes over the traditional ground-based surveying methods. While the latter methods will continue to be important in ground-truthing exercises for validation and calibration of remotely sensed data, it is generally agreed that application of remote sensing technologies for mapping of resources over large areas and with need for temporal 
replication is far much economical in comparison to traditional methods. They provide effective tool for analyzing the land use dynamics of a region, as well as for monitoring, mapping and management of natural resources, (Sreenivasulu et al., 2010 and Mas, 1999). Indeed, remote sensing approach employing the moderate resolution satellite imageries like Landsat Thematic Mapper, Landsat Enhanced Thematic Mapper Plus, SPOT Vegetation among others has widely been accepted (Alphan et al., 2009). It has gained prominence in wide range of application such as landscape resource assessment, resource monitoring, land cover change analysis, drought monitoring, and biomass estimation among others. In environmental monitoring for instance, information from satellite remote sensing can play a useful role in understanding the nature of changes in land cover/use, where they are occurring, and projecting possible or likely future change (Nori et al., 2008).

Successful application of remote sensing technology hinges on the understanding of the interaction between electromagnetic spectrum and the target land surface materials and subsequent matching of this knowledge with the application at hand. Generally, the spectral properties of the surface material as sensed by the detector is one of the most important piece of information gathered through remote sensing, besides others like viewing and illumination geometry. Depending on the nature of the target surface material as well as the path of illumination to and from the sensor, it becomes possible or not, to gather information that may infer about the properties of the target surface (Xie et al., 2008).

According to Singh (1989), digital change detection is the process of identifying differences, specifically radiances differences, by remote sensor at different times. While a variety of change detection techniques have been developed, they can generally be grouped into the following categories: algebra (differencing, rationing, and regression), change vector analysis, transformation (e.g. principal component analysis, multivariate alteration detection, Chi-square transformation), classification (post-classification comparison, unsupervised change detection, expectation-maximization algorithm) and hybrid methods, (Nori et al., 2008). General background of some of these methods has been reviewed by Singh (1989), Coppin et al. (2004) and Lu et al. (2004). Mas (1999) quantitatively compared the performance of change detection techniques and concluded that the highest accuracy was obtained using post-classification techniques.

This study aimed to generate current land cover/land use distribution map and also analyze historical Land Use Land Cover (LULC) around Ndakaini area using optical remote sensing approach. In this study, we used optical remote sensing approach to test skills of post-classification change detection technique in tropical humid highlands as well as effort of circumventing the challenges of working in a data-scarce environmental where ancillary data about historical land cover types are unavailable. We aimed to generate accurate map of land cover/land use distribution and analyze historical LULC around Ndakaini area where cloud/cloud-shadow contamination poses a serious challenge In a wider context, the results would be a key input in assessing the viability of payment for ecosystem services in Ndakaini area meant to ensure continued supply of regular and clean water to Nairobi residents.

\subsection{Study area}

Figure 1 below shows the location of the study area falling between longitude $36^{\circ} 44^{\prime} 39.46^{\prime \prime} \mathrm{E}$ and $37^{\circ} 00^{\prime} 58.03^{\prime \prime}$ E and latitude $0^{\circ} 42^{\prime} 13.28$ " S and $1^{\circ} 01^{\prime \prime} 12.72 " \mathrm{~S}$, an area at the south-eastern edges of Aberdare ranges/forest in Kenya. It's about $80 \mathrm{~km}$ north of Nairobi and $40 \mathrm{~km}$ west of Thika town and encompassing the Ndakaini Dam and its environs, administratively straddling both Gatanga and Maragua districts, Murang'a County, Kenya. Main settlement areas including Ndakaini, Makomboki, Kangari and Kariara sub-locations in Gatanga district and Kigumo division in Maragua district and together with tracts of forest areas such as Kimakia and Gatare forest stations, form the catchments of the dam. The physiographic characteristic of the region greatly influences the drainage pattern of the area and can be described in terms of three zones. The first is a zone characterized by deeply incised V- shaped valleys having slopes greater than $30 \%$ and is highly susceptible to soil erosion. This zone covers the reservoir's main catchment area, the forest reserve, the official tea belt buffering the forest -The Nyayo Tea Zone- and the influent river zones. The second zone encompasses the settlement areas, a predominantly tea growing area and where water has been dammed to contain the main water-mass. It is characterized by steep topography and soil erosion is of major concern on arable land. The area beyond the dam all the way to the confluence of Chania River forms the third zone and is predominantly a coffee plantation zone. Ng'ethu Water Treatment Works is located in this zone. Besides the Ndakaini dam, the other main hydrological features in the study area are six major rivers namely Githika, Thika, Kayuyu, Kiama, Kimakia and Chania, all influencing the drainage pattern of the area. Ndakaini dam is fed by rivers Kayuyu, Githika and Thika River and also from underground seepage.

The geology of the study area is a series of pyroclastic flows associated with the volcanic activity of the eastern Rift Valley. The terrain is made up of a series of tuffs and ashflows of varying thickness, depending on the duration of the volcanic event. The weathering grade depends on the time between the volcanic events. Thus, there is deposition of rocks consisting of materials laid down as fall or flow deposits which grade upwards from agglomeratic base through lapilli tuffs to fine grained tuffs. The major soils are histols around the mountainous 
ranges and nitosols on the foot ridges extending to the dam site. The climate/weather of the study area can be described as tropical montane, being cold and humid due to the influence of the Aberdare mountain ranges. The air temperature ranges between 9.5 to $24{ }^{\circ} \mathrm{C}$ while the water temperatures ranges between 14 and $18{ }^{\circ} \mathrm{C}$. Moreover, rainfall pattern is bi-modal, with short rains occurring from October to December and long rains from March to May. Rainfall amounts vary from 1800 to $2100 \mathrm{~mm}$ increasing as one climb-up the catchment (MoA, GATANGA DISTRICT, 2010).

The study area has rich biodiversity, both flora and fauna in the aquatic and terrestrial ecosystems. Aquatic life includes phytoplankton species as well as phragmites, aquatic macrophytes especially Typha domingensis and Cyprus papyrus on the influent fringes, zooplankton species (such as Thermocyclops Tropodiaptomus, Chaoborus, Diaphanosoma and Diaptomus) and fish species are found in the water column. Variety of birds are distributed throughout the reservoir but the highest densities are found in the influent river zones, including pelicans, Egyptian geese, storks, crested cranes, weaver birds, swallows and a variety of grebes and coons (MoA, GATANGA DISTRICT, 2010). There are indigenous and exotic tree species in the fringes and the catchment of the dam, including Prunus species, Croton megalocarpus, pines, blue gums wattles, and a myriad of forest shrubs. A common feature in the settlement areas is the occurrence of individual small-scale tea plantations, in some instances interspaced with blue gums and wattles and rows of napier-grass making some of the bounders in addition to variety of domestic animals including cows, goats, sheep and chicken.

\subsection{Methodology}

\subsection{Dataset}

According to Sobrino et al. (2004), Landsat imageries are one of the most used data for environmental studies. With an archive of data dating back to 1970 s coupled with a spatial resolution of $30 \mathrm{~m}$, a temporal resolution of 16 days (for Landsats 4 through 7) and swathe of about $183-185 \mathrm{~km}$, Landsat data proves valuable in monitoring environmental change especially more lengthy land-cover changes. Landsat satellites are equipped with sensors capable of imaging in optical and thermal portions of electromagnetic energy. Thematic Mapper (TM) is a sensor on board the Landsat 4/5 satellite while Enhanced Thematic Mapper plus $\left(\mathrm{ETM}^{+}\right)$is a sensor on board Landsat 7 satellite. Both are composed of seven bands, six of them in the visible and near infra-red, and only one band located in the thermal infra-red region. Moreover, $\mathrm{ETM}^{+}$also generates an additional panchromatic band having a spatial resolution of $15 \mathrm{~m}$, (see table 1). A review by Xie et al. (2008) provides detailed information of these two sensors.

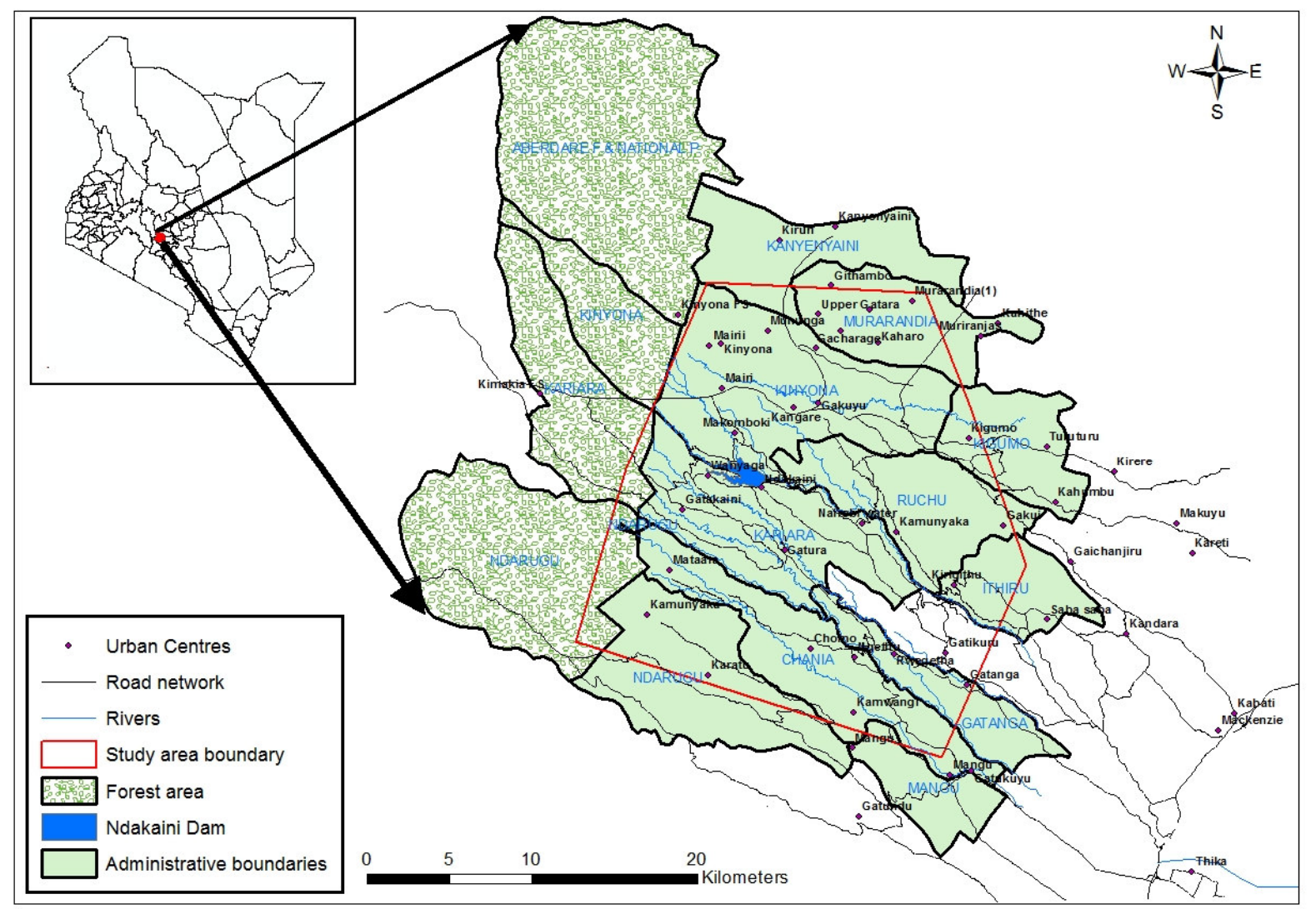

Fig. 1: Location of the study area 
Table 1: Wavelengths and band resolution of Landsat TM/ $\mathrm{ETM}^{+}$

\begin{tabular}{|l|l|l|}
\hline Band & Wavelength & Resolution \\
\hline 1 & $490+/-60 \eta \mathrm{m}$ & $30 \mathrm{~m}$ \\
\hline 2 & $575+/-75 \eta \mathrm{m}$ & $30 \mathrm{~m}$ \\
\hline 3 & $670+/-70 \eta \mathrm{m}$ & $30 \mathrm{~m}$ \\
\hline 4 & $837+/-107 \eta \mathrm{m}$ & $30 \mathrm{~m}$ \\
\hline 5 & $1692+/-178 \eta \mathrm{m}$ & $30 \mathrm{~m}$ \\
\hline 6 & $11457 \eta \mathrm{m}$ & $120 \mathrm{~m}$ \\
\hline 7 & $2190+/-215 \eta \mathrm{m}$ & $30 \mathrm{~m}$ \\
\hline $8\left(\mathrm{ETM}^{+}\right)$ & $520-900 \eta \mathrm{m}$ & $15 \mathrm{~m}$ \\
\hline
\end{tabular}

In this paper, Landsat imageries (TM and $\mathrm{ETM}^{+}$) acquired between 1985 and 2011 over WRS-2 path/row path 168 and 061 and corresponding to the study area were downloaded from Global Land Cover Facility (GLCF) and USGS website. Cloud and cloud-shadows posed a major problem as most of the available images were contaminated over most of the study area, thus limiting their use. Being a tropical humid-highland, it would normally be clouded over most part of the year, a problem also noted by Mas (1999) in his study over the Gulf of Mexico. He also cited the problem of high vegetation diversity, phenology differences and interspersion of land cover in the humid tropics where associated spectral reflectance characteristics are often not distinct, posing a challenge to digital classification. In this paper, image selection relative to temporal distribution, cloud cover and data quality meant selecting images belonging to the same period of the year and that only the clear images plus few others with minimum cloud cover were chosen but having to undergo cloud/cloud-shadow removal and refilling using mosaicing techniques before being used. While the initial plan was to get images after every fiveyear interval, it was only possible to get images dated outside the previously defined interval, a similar experience as encountered by Mas (1999). In the end, images corresponding to eight year-specific periods (referred to as anniversaries)- 1985, 1987, 1993, 1995, 2000, 2005, 2010 and 2011- were selected, with only five anniversaries finally being used for land cover mapping and change analysis (1985, 1995, 2000, 2005 and 2011). The others were merely used in filling the cloud/cloud-shadow gaps, (Table 2). The images were imported into ERDAS Imagine 2011 software where they were converted into user-friendly format that allowed assessing quality of the images, pre-processing and implementing digital land-cover classification. ArcGIS 2010 software was used for analysis of processed images. Besides the satellite, other data such as administrative maps, project boundary maps, road network, and urban centers were also used. The flowchart in Figure 2 illustrates the approach/framework followed in this paper to implement land-cover change analysis in tropical humid area. 


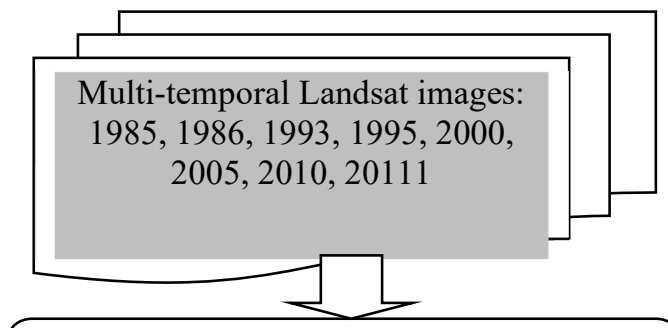

Geometrical correction: geo-registration, sub-setting

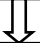

Atmospheric correction: cloud/shadow correction, radiance calibration, conversion to at-satellite reflectance

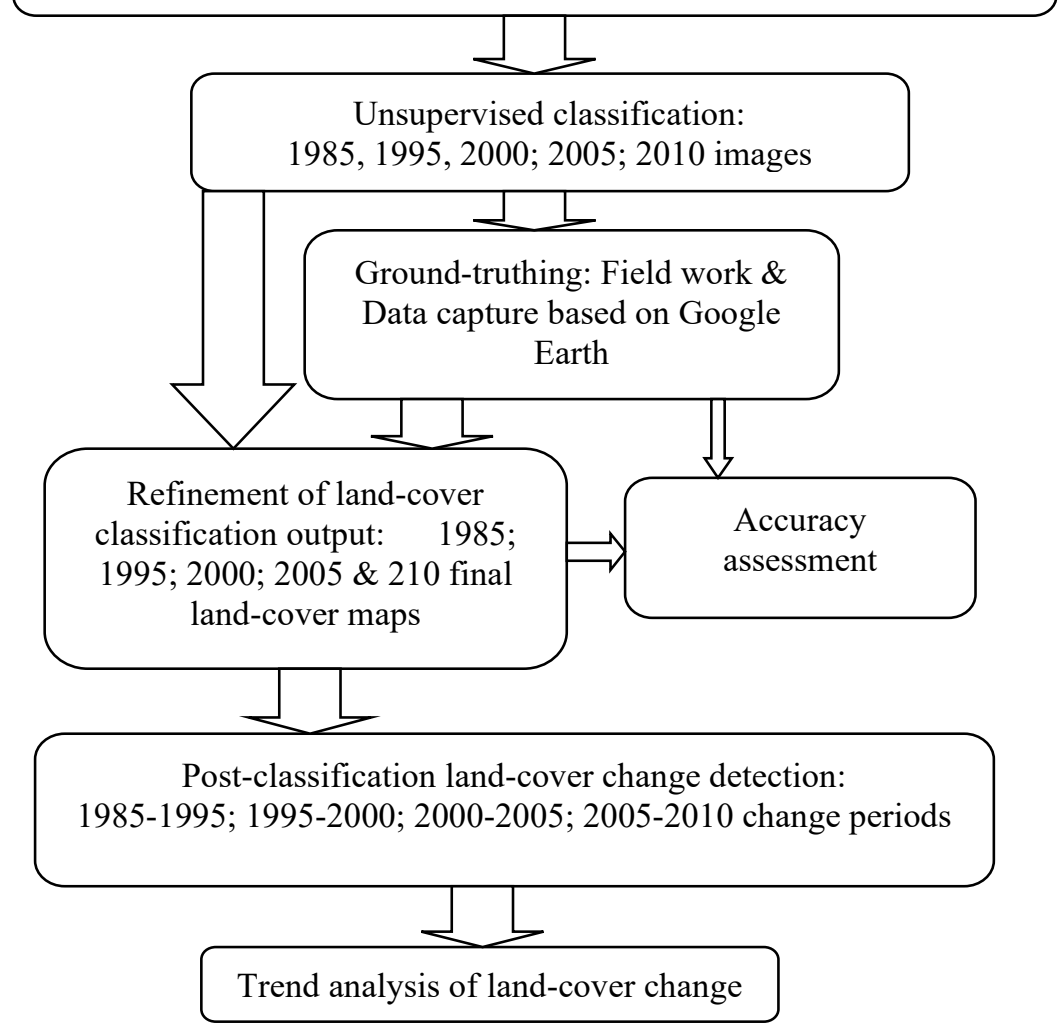

Fig. 2: Flowchart illustrating land-cover change analysis approach/design

\subsection{Pre-processing of satellite images}

Prior to processing of image-based products and information analysis, the satellite images were first pre-processed to lender them usable for processing and analysis operations. The images acquired from GLCF and USGS websites were already geometrically rectified and projected to UTM projection by the vendor and thus no further geometric rectification was needed. However, radiometric and atmospheric corrections were necessary as most of the images were contaminated.

Table 2: Description of selected images

\begin{tabular}{|c|c|c|c|}
\hline Date of acquisition & $\begin{array}{l}\text { Julian day } \\
\text { (JD) }\end{array}$ & $\begin{array}{ll}\text { Landsat } & \text { sensor/ } \\
\text { satellite } & \\
\end{array}$ & Final use of the image \\
\hline 1985-Jan-18 & 18 & TM5 & Final analysis \\
\hline 1987-Feb-25 & 56 & TM5 & Correcting cloud \& shadow of 1985 \\
\hline 1993-Feb-17 & 48 & TM4 & Correcting cloud \& shadow of 1995 \\
\hline 1995-Jan-30 & 30 & TM5 & Final analysis \\
\hline 2000-Feb-21 & 52 & $\mathrm{ETM}^{+} 7$ & Final analysis \\
\hline 2005-Feb-18 & 49 & $\mathrm{ETM}^{+} 7$ & Final analysis \\
\hline 2010-Feb-08 & 39 & TM5 & Correcting cloud \& shadow of 2011 \\
\hline 2011-Jan-10 & 10 & TM5 & Final analysis \\
\hline
\end{tabular}




\subsection{Cloud/cloud-shadow removal and gap filling}

Cloud/cloud-shadow detection followed the approach employed by Meng et al. (2009). It involves using Landsat image bands 3 and 4 to detect pixels that are contaminated by cloud/cloud-shadows through thresholding technique and Boolean operations. The lowest value of cloud-covered pixels was identified by examining the image histogram of band 4 , the value then used as a threshold to generate cloud covered/cloud-free binary masks. Identification of cloud-shadow pixels followed the same procedure. However, since deep and clear water bodies have relatively similar spectral characteristic as the cloud-shadows, then use of band 3 was necessary. While water bodies reflect equal amount of radiation in bands 3 and 4, cloud-shadows on the other hand tends to reflect more energy in band 4 than in band 3. Thus, based on ratioing of band 4 to band 3, water pixels having a ratio close to unity were masked off and a mask of cloud-shadow pixels with a ratio about 1.3 generated. Both masks of cloudcovered pixels and pixels contaminated by cloud-shadows were mosaiced, the product then used to mask off colocated pixels in each band resulting in cloud-free and cloud-shadow-free image bands. These procedures were implemented for each of the contaminated images, using image-based threshold summarized in Table 3. Subsequent filling of cloud/cloud-shadow gaps involved matching images of the same period for anniversaries that were not far apart. This way, images that would be used for processing products and information analysis were improved albeit some few patches that could not get co-located pixels from their respective matching anniversaries. Table 3: Image-based Threshold values used in cloud/cloud-shadow removal

\begin{tabular}{|c|c|c|c|c|}
\hline $\begin{array}{l}\text { Date of } \\
\text { acquisition }\end{array}$ & $\begin{array}{l}\text { Cloud/cloud- } \\
\text { shadow cover }\end{array}$ & $\begin{array}{l}\text { Cloud } \\
\text { correction } \\
\text { threshold } \\
\text { on band 4) }\end{array}$ & $\begin{array}{l}\text { Cloud-shadow } \\
\text { correction threshold } \\
\text { (based on band } 4 \text { and } \\
\text { ration of band } 4 \text { to } \\
\text { band 3) }\end{array}$ & Final use of the image \\
\hline 1985-Jan-18 & Contaminated & $>95$ & $<55 ; \quad>1.3$ & Final analysis \\
\hline 1987-Feb-25 & Contaminated & $>95$ & $<55$ & $\begin{array}{l}\text { Correcting cloud \& } \\
\text { shadow of } 1985\end{array}$ \\
\hline 1993-Feb-17 & Contaminated & $>95$ & $<62 ;>1.3$ & $\begin{array}{l}\text { Correcting cloud \& } \\
\text { shadow of } 1995\end{array}$ \\
\hline 1995-Jan-30 & Contaminated & $>95$ & $>1.02$ & Final analysis \\
\hline 2000-Feb-21 & Very clear & Very clear & Very clear & Final analysis \\
\hline 2005-Feb-18 & $\begin{array}{l}\text { Clear } \quad \text { with } \\
\text { stripes }\end{array}$ & Clear ( with stripes) & Clear (with stripes) & Final analysis \\
\hline 2010-Feb-08 & Contaminated & $>95$ & $>1.02$ & $\begin{array}{l}\text { Correcting cloud \& } \\
\text { shadow of } 2011\end{array}$ \\
\hline 2011-Jan-10 & Contaminated & $>95$ & $>1.02$ & Final analysis \\
\hline
\end{tabular}

\subsection{Radiometric correction: radiance calibration and conversion to top-of-atmosphere reflectance}

In most raw remote sensing imageries, measured radiance of the earth surface is represented in the form of digital numbers (DN) which are calibrated to fit a certain range of values. In the case of Landsat Thematic Mapper and Enhance Thematic Mapper plus, these radiance values are scaled to numbers between 0 to 255 . Conversion of DN back into absolute radiance is a necessary step when the objective is to perform comparative analysis of several images acquired at different times. Subsequent conversion to radiance to top-of-atmosphere reflectance is needed for a more accurate comparison of images across different dates.

In this paper, the conversion from DN to spectral radiance $\left(\mathrm{L}_{\lambda}\right)$ followed the procedure applied by Sobrino et al. (2004), using calibration coefficients included in each scene's metafile also provided in the look-up table (table 4) below), as: $\mathrm{L}_{\lambda}=\mathrm{G}_{\text {rescale }} * \mathrm{DN}+\mathrm{B}_{\text {rescale }}$

Equn 1

Conversion of radiance to top of atmosphere or exo-atmospheric reflectance was implemented to adjust the sensor reflectance from unwanted influences of factors brought about by the differential solar elevation and positional relationship between the Earth and the Sun at different times of the year and place. Here, the procedure applied by Qinqin et al. (2010) was followed, as:

$\mathrm{P}=\pi \mathrm{L}_{\lambda} \mathrm{d}_{\mathrm{s}} * \mathrm{~d}_{\mathrm{s}} /(\mathrm{ESUN} * \operatorname{Cos} \theta)$

Eqn 2

where $L_{\lambda}$ is spectral radiance from equation $1, d_{s}$ is Earth-Sun distance in astronomical units and varies with time of the year (usually given in nautical Handbook for each Julian Day or interpolation, Table 5), ESUN is mean exo-atmospheric solar irradiance for each waveband, given in Table 6 , and $\theta$ is solar zenith angle for each scene, provided in scene's metafile. It is notable that the thermal channel (band 6) isn't included.

\subsection{Implementing Land cover mapping and post-classification change analysis}

Once the images were corrected, they were ready for land cover classification. Digital image classification can be 
broadly categorized into two types viz. supervised and unsupervised. Supervised classification involves creation of training sets followed by classification step. Conversely, in the unsupervised classification approach, the image data are classified by aggregating them into the natural spectral groupings or clusters, present in the image on the basis of clustering algorithms. In this method, image interpreting software separates the pixels in an image based upon their reflectance values into classes with no direction from the analyst. According to Xie et al. (2008), unsupervised classification is often used in thematic mapping from imagery as it is easy to apply and widely available in image processing and statistical software packages. They have noted that K-MEAN and ISODATA clustering algorithms are the two most frequently used methods. S. Jr. et al. (2003) tested several methods of mapping forested pixels and concluded that ISODATA unsupervised classification algorithm produced the best results. This algorithm assigns pixels to the most probable cluster based on spectral similarity to the presumed mean. Belongingness is established iteratively based on the most common cluster to which the pixel may associate.

Table 4: Calibration coefficients for Landsat sensors

\begin{tabular}{|c|c|c|c|c|c|c|c|c|}
\hline \multirow{2}{*}{\multicolumn{9}{|c|}{$\begin{array}{l}\text { L5 TM Post-Calibration Dyanamic Ranges for U.S. Processed NLAPS Data } \\
\text { Snectral Radiances Lmin and }\end{array}$}} \\
\hline  & & & & in and $\mathrm{L}$ & $\operatorname{ax}$ in $W$ & $\mathrm{~m}^{2} \cdot$ sr.un & 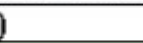 & \\
\hline \multirow{3}{*}{$\begin{array}{c}\text { Processing } \\
\text { Date }\end{array}$} & \multicolumn{4}{|c|}{ From March 1, 1984} & \multirow{2}{*}{\multicolumn{4}{|c|}{ After May 5, 2003}} \\
\hline & \multicolumn{4}{|c|}{ To May 4, 2003} & & & & \\
\hline & Lmin & Lmax & $\mathrm{G}_{\text {rescale }}$ & B rescale $_{\text {re }}$ & Lmin & Lmax & $\mathbf{G}_{\text {rescale }}$ & $\mathbf{B}_{\text {rescale }}$ \\
\hline 1 & -1.52 & 152.10 & 0.602431 & -1.52 & -1.52 & 193.0 & 0.762824 & -1.52 \\
\hline 2 & -2.84 & 296.81 & 1.175100 & -2.84 & -2.84 & 365.0 & 1.442510 & -2.84 \\
\hline 3 & -1.17 & 204.30 & 0.805765 & -1.17 & -1.17 & 264.0 & 1.039880 & -1.17 \\
\hline 4 & -1.51 & 206.20 & 0.814549 & -1.51 & -1.51 & 221.0 & 0.872588 & -1.51 \\
\hline 5 & -0.37 & 27.19 & 0.108078 & -0.37 & -0.37 & 30.2 & 0.119882 & -0.37 \\
\hline 6 & 1.2378 & 15.303 & 0.055158 & 1.2378 & 1.2378 & 15.303 & 0.055158 & 1.2378 \\
\hline 7 & -0.15 & 14.38 & 0.056980 & -0.15 & -0.15 & 16.5 & 0.065294 & -0.15 \\
\hline
\end{tabular}

Table 5: Earth-Sun distance interpolated from the look-up table

\begin{tabular}{|l|l|l|l|}
\hline Path_row & Julian Day & ds & Solar elevation angle, $\boldsymbol{\theta}$ \\
\hline $168 \_061$ & 18 & 0.98385 & 49.0493977 \\
\hline $168 \_061$ & 56 & 0.98330 & 48.6690678 \\
\hline $168 \_061$ & 48 & 0.98989 & 50.2 \\
\hline $168 \_061$ & 30 & 0.98814 & 46.7308389 \\
\hline $168 \_061$ & 52 & 0.98509 & 45.2738594 \\
\hline $168 \_061$ & 49 & 0.98899 & 56.5049322 \\
\hline $168 \_061$ & 39 & 0.98835 & 55.4609572 \\
\hline
\end{tabular}

Table 6: Mean exo-atmospheric solar irradiance for each waveband, ESUN

\begin{tabular}{|c|c|c|c|c|}
\hline TM Solar Exoatmospheric Spectral Irradiances \\
\hline Units: & \multicolumn{5}{|c|}{ ESUN = W/(m².um) } \\
\hline Model : & Neckel and Labs & Chance Spectrum CHKUR \\
\hline Band & Landsat 4 & Landsat 5 & Landsat 4 & Landsat 5 \\
\hline $\mathbf{1}$ & 1958 & 1957 & 1957 & 1957 \\
\hline $\mathbf{2}$ & 1828 & 1829 & 1825 & 1826 \\
\hline $\mathbf{3}$ & 1559 & 1557 & 1557 & 1554 \\
\hline $\mathbf{4}$ & 1045 & 1047 & 1033 & 1036 \\
\hline $\mathbf{5}$ & 219.1 & 219.3 & 214.9 & 215.0 \\
\hline $\mathbf{7}$ & 74.57 & 74.52 & 80.72 & 80.67 \\
\hline
\end{tabular}

In this paper, ISODATA unsupervised classification was first implemented using ERDAS IMAGINE prior to field campaign. For each of the five anniversary-images being analyzed, the result of the iterations were six (6) classified land cover types, the number having been determined a priori during an earlier reconnaissance field visit on January 2012. These classes are forest/woodlots; tea farms; water bodies; moisture deficit vegetation; dry/senesced vegetation; and bareland. The result of unsupervised classification of 2010 anniversary was used to guide a field campaign which was conducted during the dry season of February 2012. Although the study area does not experience severe dry spell, it was possible to discriminate annuals from perennials. Land use/cover description data was collected over 74 sample points representatives of all typical land-cover types. Google Earth (having IKONOS image acquired in 2000 as the background) was also used to capture additional data from 204 sample points (mainly tea plantation and forest/woodlot) meant to compliment the ground-truth data.

Given the scarcity of information regarding the distribution of land cover with respect to the selected anniversaries matching image acquisition dates (i.e. 1985, 1995, 2000, 2005 and 2010), it was only logical to refine the previous results of unsupervised classification to generate final land use/cover maps. The main assumption was that apart from areas under annual crop fields, the current distribution of the remaining land cover types such as woodlots/forest, water bodies, perennial crops like tea were very likely to have existed even in the historical 
anniversaries, allowing therefore the use of ground-truth data to a fair degree of accuracy. A sample of this groundtruth data was superimposed onto the results of unsupervised classification for each of the anniversaries being analyzed for purpose of refining the output land cover. Given the ambiguity presented by the annual crop fields (ca maize, vegetables, nappier grass), such cover types were designated as 'others' during the refinement of unsupervised classification. The use of producers' and users' error, overall accuracy as well as Khapa statistics have often been used as robust measure of accuracy and assessment of error patterns of the classification maps generated from digital image classification, (Mas, 1999; Xie et al., 2008; Nori et al., 2008). In this study, respective confusion matrices and Kappa statistics were generated as a way of measuring the accuracy of the maps.

Due to the problem of cloud and shadow contaminated pixels (remaining even after applying the filling masks), post-classification land-cover change analysis was undertaken between target anniversaries based on colocated pixels that were cloud/shadow free. Four periods were targeted for analysis beginning with the anniversary prior to dam construction to as late as 2010/2011 anniversary, thus 1985 to $1995 ; 1995$ to 2000; 2000 to 2005; and 2005 to 2010/2011 anniversary periods. The analysis focused on establishing the change in extent of surface areas of key land cover types and determining where there was occurrence of land cover change and between which land cover categories.

\subsection{Results \& Discussion}

\subsection{Effect of cloud and cloud-shadow correction}

Being a tropical humid highland, Ndakaini Dam and it's surrounding is usually engulfed in cloud and cloudshadows for most part of the year even during the supposed dry season. This present a challenge to the application of optical remote sensing as both clouds and shadows contaminate the signal from the land surface. In this study, images that had minimal contamination were selected and correction implemented using co-located images closely matching the temporal range of the respective target anniversaries as presented in table 3 . The selected images representing 1985, 1995 and 2011 anniversaries had some parts of the study area contaminated, (about 28\%, 5\% and $43 \%$ respectively). By implementing cloud and cloud-shadow correction, the gaps were reduced immensely (e.g. $90 \%$ for the 1985 image and $82 \%$ for the 2011 image). Figures 2 shows the improvement achieved after implementing cloud and shadow correction in the selected image of 1985 anniversary.


Fig. 2: Effect of cloud correction of Landsat TM image (subset) of Jan. 1985, (from left to right: before and after correction

\subsection{Accuracy assessment}

Fig. 3 below shows the distribution of ground-truth points collected from field campaign as well as Google Earth environment. A total of 278 points were used to assess the accuracy of each of the generated land cover map and the result is summarized in Table 7.

Land cover classification outputs of 2000, 2005 and 2010 had fairly high level of overall accuracy $(64 \%, 79 \%$ and $68 \%$ respectively) and Kappa statistic ( $0.47,0.69$ and 0.53 respectively) compared to similar measures in 1985 and 1995 classification outputs. Having used ground-truth data collected from field campaign of 2011 and those captured from Google Environment whose background image was a very high resolution image of acquired over the study area in 2000, the extent to which these data matched the imaged realities in respective anniversaries can be associated to the reflected accuracy measure of respective anniversaries. Land use, unlike geology, is seasonally dynamic and indeed is more changing, (Sreenivasulu et al., 2010). Thus, likely mis-matches are expected to be 
more predominant and sharp in 1985 and 1995 but less sharper in 2000, 2005 and 2010 anniversaries. Mis-match is expected to be relatively higher in land use/land cover category experiencing intense land use/cover dynamics such as seasonal/annuals (or others), suggesting why the producers accuracy of this category was indeed low in 1985, 1995 and even 2000 anniversaries (42\%, 30\% and 38\% respectively).

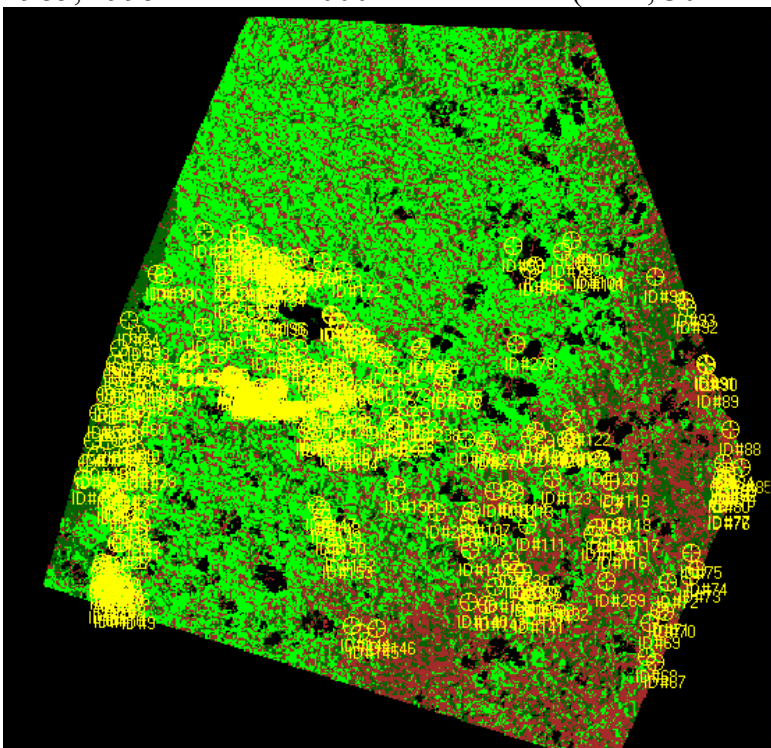

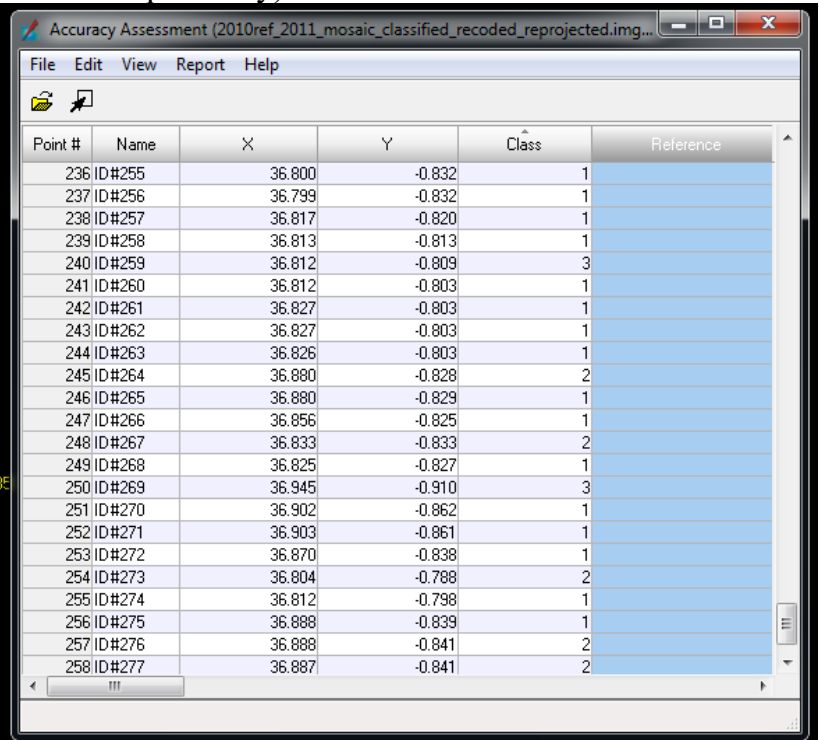

Fig. 3: Distribution of ground-truth points (based on field campaign and Google Earth)

Table 7: Accuracy measures of generated land cover maps

\begin{tabular}{|c|c|c|c|}
\hline & Producers Accuracy $(\%)$ & Users Accuracy (\%) & KAPPA $\left(K^{\wedge}\right)$ STATISTICS \\
\hline \multicolumn{4}{|c|}{ January 18, 1985 (cloud/shadows corrected) } \\
\hline Tea Plantation & $79 \%$ & $45 \%$ & 0.25 \\
\hline Forest/woodlots & $69 \%$ & $76 \%$ & 0.64 \\
\hline \multirow[t]{2}{*}{ Others } & $42 \%$ & $71 \%$ & 0.51 \\
\hline & \multicolumn{2}{|l|}{ Overall Accuracy $=60 \%$} & Overall Kappa Statistics $=0.42$ \\
\hline \multicolumn{4}{|c|}{ January 30, 1995 (cloud/shadows corrected) } \\
\hline Tea Plantation & $86 \%$ & $44 \%$ & 0.23 \\
\hline Forest/woodlots & $77 \%$ & $79 \%$ & 0.69 \\
\hline \multirow[t]{2}{*}{ Others } & $30 \%$ & $74 \%$ & 0.56 \\
\hline & \multicolumn{2}{|l|}{ Overall Accuracy $=60 \%$} & Overall Kappa Statistics $=0.42$ \\
\hline \multicolumn{4}{|c|}{ February 21, 2000} \\
\hline Tea Plantation & $86 \%$ & $45 \%$ & 0.25 \\
\hline Forest/woodlots & $79 \%$ & $83 \%$ & 0.75 \\
\hline \multirow[t]{2}{*}{ Others } & $38 \%$ & $83 \%$ & 0.71 \\
\hline & \multicolumn{2}{|l|}{ Overall Accuracy $=64 \%$} & Overall Kappa Statistics $=0.47$ \\
\hline \multicolumn{4}{|c|}{ February 18, 2005} \\
\hline Tea Plantation & $97 \%$ & $67 \%$ & 0.55 \\
\hline Forest/woodlots & $70 \%$ & $80 \%$ & 0.71 \\
\hline \multirow[t]{2}{*}{ Others } & $74 \%$ & $92 \%$ & 0.87 \\
\hline & \multicolumn{2}{|l|}{ Overall Accuracy $=79 \%$} & Overall Kappa Statistics $=0.69$ \\
\hline \multicolumn{4}{|c|}{ February 08, 2010 (cloud/shadows corrected) } \\
\hline Tea Plantation & $95 \%$ & $57 \%$ & 0.40 \\
\hline Forest/woodlots & $58 \%$ & $76 \%$ & 0.65 \\
\hline \multirow[t]{2}{*}{ Others } & $58 \%$ & $81 \%$ & 0.69 \\
\hline & \multicolumn{2}{|l|}{ Overall Accuracy $=68 \%$} & Overall Kappa Statistics $=0.53$ \\
\hline
\end{tabular}

3.3 Land use / land cover change

Historical analysis of time series of Landsat images proved valuable in providing insights about the evolving land 
use dynamics in Ndakaini area. In order to quantify land cover change results, a similar approach used by Nori et al. (2008) was also applied where total surface area for each land use/cover types was tabulated and the respective trends across the years examined, demonstrating the kind of land cover changes that occurred during the period of analysis, namely "from-to" information. Analysis of multi-temporal images of 1985, 1995, 2000, 2005 and 2010/11 points to a glaring evidence of spatial and temporal land use dynamics especially among three major land cover classes namely tea plantation, forest or woodlots and annual crop fields, all differing in their respective general trend of change and with regard to the intensity of inter-class conversion. A summary of these trends is captured in table 8 and figure 4 below.

Table 8: Extent of key land covers types in selected anniversaries

\begin{tabular}{|l|l|l|l|l|l|}
\hline Land cover type & $\mathbf{1 9 8 5}$ & $\mathbf{1 9 9 5}$ & $\mathbf{2 0 0 0}$ & $\mathbf{2 0 0 5}$ & $\mathbf{2 0 1 0 / 1 1}$ \\
\hline Tea plantation $(\mathrm{Ha})$ & 20,368 & 20,738 & 19,256 & 21,420 & 23,872 \\
\hline Forest/woodlot $(\mathrm{Ha})$ & 13,332 & 12,096 & 14,609 & 15,985 & 9,643 \\
\hline Annual crop fields (Ha) & 19,550 & 20,228 & 19,178 & 15,571 & 15,800 \\
\hline
\end{tabular}

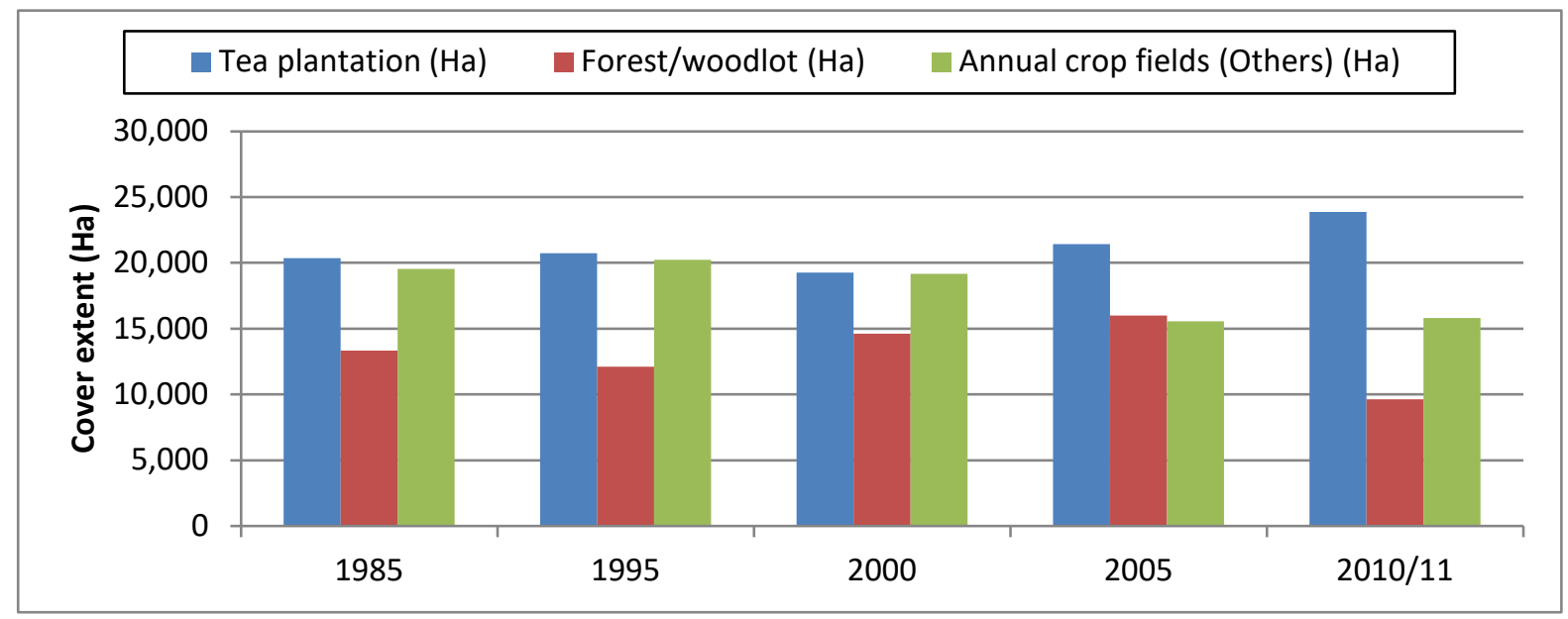

Fig. 4: General land cover change trend among the three major land cover categories

The overall extent of tea plantation seemed to have increased between 1985 and 2010/11, with minimum and maximum range being 20,368 ha in 1985 and 23,872 ha in 2010/11 respectively. Apart from the 1995-2000 period where the extent of tea plantation apparently decreased by $7 \%$ (1,482 ha), the other change analysis periods showed an increase; $2 \%$ (370 ha) in 1985-1995 period, 11\% (2,164 ha) in 2000-2005 period and 11\% (2,452 ha) in $2005-$ 2010/11 periods. Figures 5 illustrate these dynamics evidenced in tea plantation, showing the spatial distribution of the gain or loss in tea areas while Table 9 summarizes the land use/cover dynamics/conversion. Tea has remained the main cash crop in the area, and therefore farmers have continued to increase the area under the crop to secure their income, apparently explaining the increase in the overall area under tea between 1985 and 2010/11. However, the apparent loss of tea cover witnessed during 1995 - 2000 period, may be attributed to the gradual filling-up of Ndakaini dam, with water replacing areas initially occupied by tea. The dam was completed in 1994 but took 2 years to fill up. In the same period, woodlot development and promotion effort were intensified, perhaps the outcome of these campaigns taking toll of tea cover in areas beyond the dam.

The dynamics of forest/woodlot cover showed an intermittent increase and decrease but accumulating to an overall decline from 13,332 ha to 9,543 ha between 1985 and 2010/11 respectively. While the period between 1985 and 1995 was apparently occasioned by $9 \%$ (1,236 ha) loss of forest cover, the dynamics were of different trends in 1995-2000 and 2000-2005 change analysis period, typified by increase of the extent of forest/woodlot cover by about $21 \%(2,513 \mathrm{ha})$ and $9 \%(1,376 \mathrm{ha})$ respectively. In the subsequent period between 2005 and $2010 / 11$, however, the trend took a negative direction, reflected by an accelerated loss of forest/woodlot cover by about 40\% (6,342 ha). Figure 6 illustrates these dynamics evidenced in forest/woodlot cover, showing the spatial distribution of the respective gain or loss while Table 9 summarizes the land use/cover dynamics/conversion. The period between 1985 and 1995 was evidenced with huge landscape transformation, particularly the clearance of vegetation and earth excavation to pave way for dam construction. The associated dynamics within and beyond the dam area may perhaps have occasioned the decline in forest/woodlot cover in the same period. On a different note, the increase in woodlot between 1995-2005 may perhaps be attributed to intensified efforts in woodlot 
development and promotion as alternative livelihood option. On the other hand, the period 2005-2010 associated with accelerated reduction of woodlot cover, was occasioned by a number of factors key among them being; the ban of timber harvesting from government forests thus leading to high demand from the farms, increasing prices of tree products and demand from tea factories occasioned by change of energy source from furnace oil to firewood in their kilns. Tea factories remain a major consumer of woodlots in the area and while that level may currently be unsustainable, it is commendable that a number of factories have acquired land to plant woodlots for their future use in other parts of Central Kenya.

Similar to forest/woodlot cover, the dynamics of annual crop fields and other cover types was also occasioned by intermittent increase and decrease accumulating to an overall decline from 19,550 ha to 15,800 ha between 1985 and 2010/11 respectively. Between 1985 and 1995, the land use dynamics apparently reflected a 3\% (678 ha) slight increase in the extent of annual crop fields (others), but later evolving a negative trend in the subsequent change analysis periods, i.e. a decline by 5\% (1,050 ha) between 1995 and 2000 and 19\% (3,607 ha) between 2000 and 2005. In the 2005-2010/11 period, however, the trend reflected a slight increase $(1 \%, 229$ ha) in the extent of areas under annual crops (others). Apparently, these trends oppositely matches the trends evidenced in forest/woodlot cover, albeit inconsistencies in measured values of either covers. Seemingly, in the periods when establishment of woodlots was intensifying, areas under annuals crop fields (others) were being decimated perhaps to pave way for woodlot establishment. Accelerated harvesting of these woodlots witnessed in 2005-2010/11 period would potentially revert some of these areas back to annual crop fields (or others), perhaps explaining the slight increase of the latter in this period. Figures 7 illustrates these dynamics evidenced in annual crop cover (others), showing the spatial distribution of the respective gain or loss while Table 9 summarizes the land use/cover dynamics/conversion.
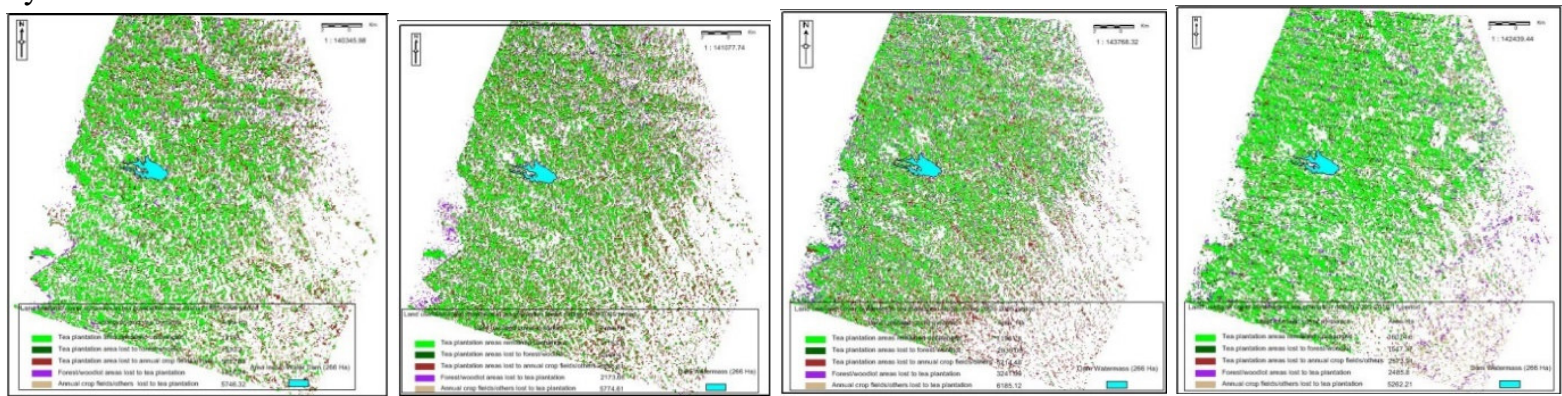

Fig. 5: Land use/land cover dynamics in tea plantation areas (from left to right: 1985-1995, 1995-2000, 2000-2005, 2005-2010/11)
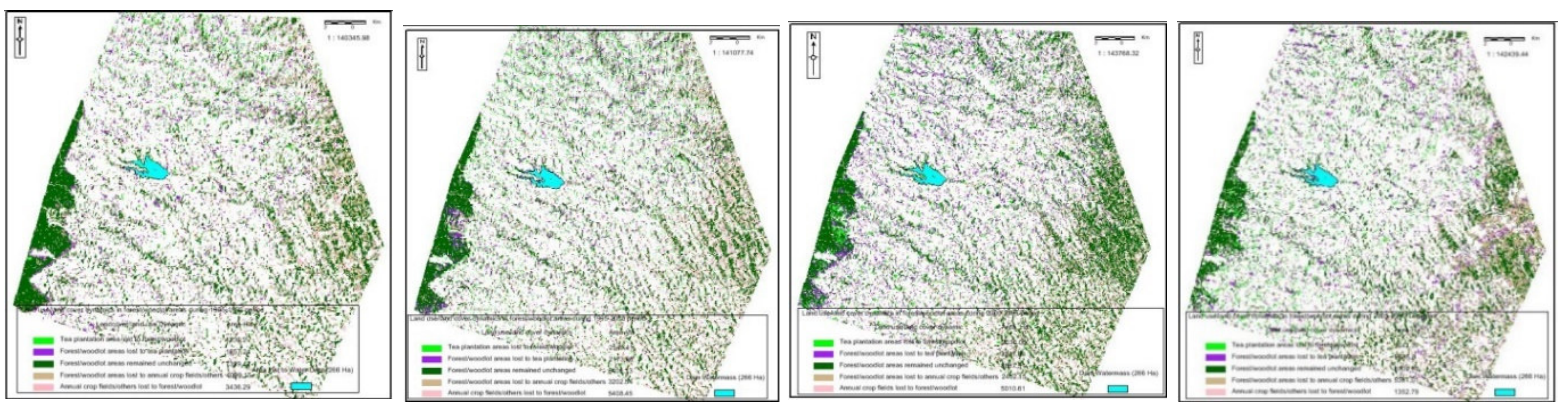

Fig.6: Land use/land cover dynamics in forest/woodlot areas (from left to right: 1985-1995, 1995-2000, 20002005, 2005-2010/11)


Fig.7: Land use/land cover dynamics in annual crop fields (others) areas (from left to right: 1985-1995, 1995-2000, 2000-2005, 2005-2010/11) 
Table 9: Trend of land use/land cover dynamics and evolving inter-class conversion

\begin{tabular}{|c|c|c|c|c|}
\hline $\begin{array}{l}\text { Land cover dynamics } \\
\text { /conversion }\end{array}$ & $\begin{array}{l}1985-1995 \\
(\mathrm{Ha})\end{array}$ & $\begin{array}{l}1995-2000 \\
\text { (Ha) }\end{array}$ & $\begin{array}{l}2000-2005 \\
\text { (Ha) }\end{array}$ & $\begin{array}{l}\text { 2005-2010/11 } \\
\text { (Ha) }\end{array}$ \\
\hline \multicolumn{5}{|c|}{ Target land cover class/ category: Tea plantation } \\
\hline Remained unchanged & 13,135 & 11,163 & 11,961 & 16,075 \\
\hline Changed to forest/woodlot & 1,330 & 2,549 & 2,030 & 1,547 \\
\hline $\begin{array}{l}\text { Changed to other annual crop- } \\
\text { fields }\end{array}$ & 5,832 & 6,897 & 5,214 & 2,574 \\
\hline Changed to water body & 66 & & & \\
\hline \multicolumn{5}{|c|}{ Target land cover class: Forest/woodlot } \\
\hline Remained unchanged & 7,329 & 6,406 & 8,887 & 6,710 \\
\hline Changed to tea plantation & 1,857 & 2,174 & 3,242 & 2,486 \\
\hline $\begin{array}{l}\text { Changed to other annual crop- } \\
\text { fields }\end{array}$ & 4,089 & 3,203 & 2,402 & 5,381 \\
\hline Changed to water body & 58 & & & \\
\hline \multicolumn{5}{|c|}{ Target land cover class: Annual crop fields } \\
\hline Remained unchanged & 10,306 & 8,913 & 7,948 & 7,831 \\
\hline Changed to tea plantation & 5,746 & 5,775 & 6,185 & 5,262 \\
\hline Changed to forest/woodlot & 3,436 & 5,408 & 5,011 & 1,353 \\
\hline Changed to water body & 25 & & & \\
\hline
\end{tabular}

From the fore-going, it is clear that the three land uses/covers followed different and inconsistent temporal land use dynamics across the change-analysis periods, while experiencing different intensity of dynamics. A comparison of the intensity of the temporal land use dynamics among the three main land use /land cover types is summarized by Figure 8 below. In 1985-1995 change-analysis period, land use dynamics were substantially intensive in sites previously under annual crops fields (others) and forest /woodlots (47\% and $45 \%$ respectively) but moderate in sites under tea plantation (35\%). In 1995-2000 change-analysis periods, land use dynamic was more intensive in sites previously under annual crops fields compared to those under forest /woodlots and tea plantation $(55 \%, 44 \%$, and $46 \%$ respectively). A similar scenario was evidenced in 2000-2005 change-analysis period, where the intensity of dynamics ranged at 58\%, 39\%, and 38\% respectively. In 2005-2010/11 changeanalysis period, land use dynamic was substantially low in sites previous under tea plantation but moderate in those under annual crop fields and forest/woodlots (19\%, $42 \%$ and $49 \%$ respectively). 


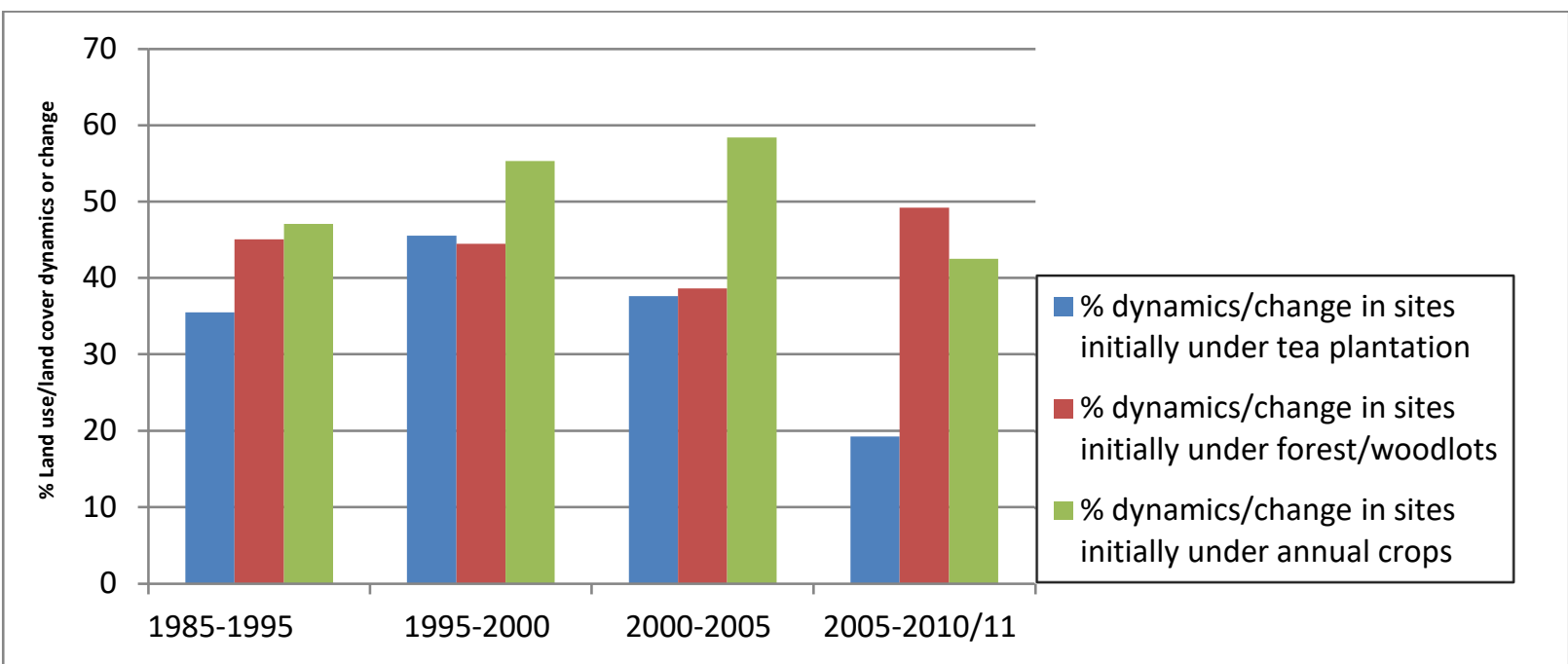

Fig. 8: A comparison of the intensity of the temporal land use dynamics among the three main land use /land cover types

The ongoing temporal land use dynamics generate land cover matrices with evolving loss or gain in the extent of key land cover classes with losers and gainers varying and again inconsistent across change-analysis periods, (see Figure 9 below). The translating rate of gain/loss is equally inconsistent as shown in Table 10 below. During the change-analysis period of 1985-1995, forest/woodlot cover experienced an overall spatial loss (about 9\%) while the other two covers (tea plantation and annual crop fields) experienced an overall spatial increment (2\% and 3\% respectively). In 1995-2000 change analysis period, forest/woodlot cover experienced an overall spatial increment (21\%) while tea plantation and annual crop fields experienced an overall spatial decrement $(7 \%$ and $5 \%$ respectively). In 2000-2005 change-analysis period, both tea plantation and forest/woodlot cover experienced a spatial increment (11\% and 9\% respectively) while annual crop fields experienced a spatial decrement (19\%). In 2005-20010/11 change-analysis period, forest/woodlot cover experience a huge spatial decrement (40\%) while tea plantation and annual crop fields experienced a spatial increment (11\% and $1 \%$ respectively).

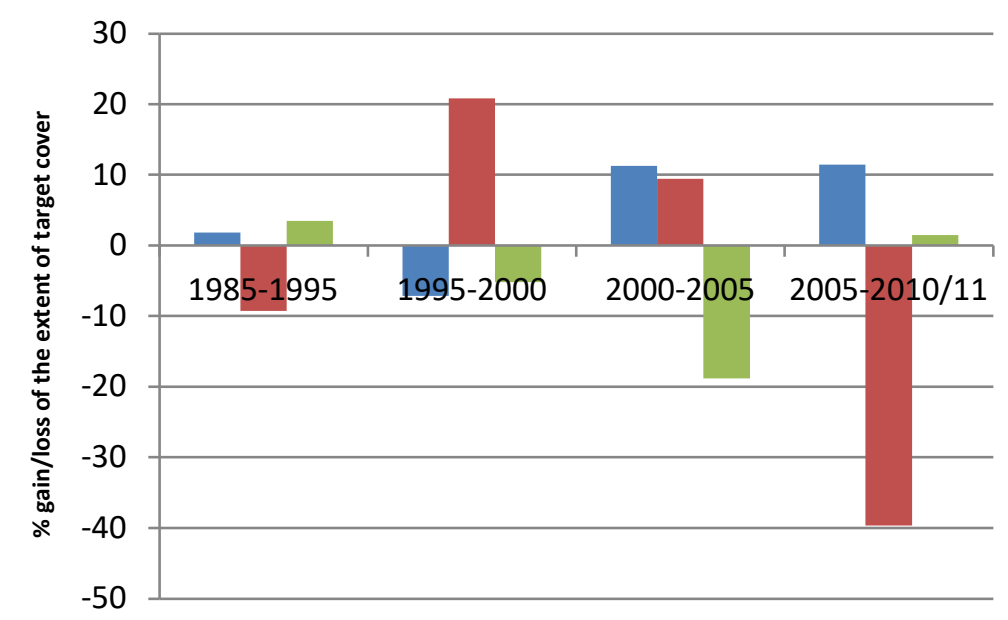

$\%$ Gain/loss of tea plantation areas

\% Gain/loss of forest/woodlot areas

\% Gain/loss of areas under annual crops

Fig. 9: Evolving loss or gain in the extent of key land cover classes across change-analysis period

Table 10: Estimated rate of gain/loss of extent of target cover across change-analysis periods

\begin{tabular}{|c|c|c|c|c|c|}
\hline Change analysis period & $\begin{array}{l}1985-1995 \\
(\mathrm{Ha})\end{array}$ & $\begin{array}{l}1995-2000 \\
(\mathrm{Ha})\end{array}$ & $\begin{array}{l}2000-2005 \\
(\mathrm{Ha})\end{array}$ & $\begin{array}{l}2005-2010 / 11 \\
(\mathrm{Ha})\end{array}$ & $\begin{array}{l}\text { Average } \\
(\mathrm{Ha})\end{array}$ \\
\hline Annual rate of gain/loss of tea plantation areas & 37 & -296 & 433 & 490 & 166 \\
\hline Annual rate of gain/loss of forest/woodlot areas & -124 & 503 & 275 & -1268 & -154 \\
\hline
\end{tabular}

\subsection{Conclusion}

As noted by Tottrup (2007), classification in highland regions is complicated by the complex spatial and structural pattern of tropical landscapes as well as by topography. Cloud and cloud-shadows proves to be a major impediment of land cover change analysis, especially where images acquired at the same period of the year are needed to 
reduce vegetation phenology differences. As the problem of availability of cloud-free images in tropical regions is very common, gap-filling followed by mosaicing techniques are valuable in rendering images ready for use in land cover change analysis as evidenced in this paper. Here, the selected images representing 1985, 1995 and 2011 anniversaries had some parts of the study area contaminated, (about 28\%, 5\% and 43\% respectively). By implementing cloud and cloud-shadow correction, the gaps were reduced immensely (e.g. $90 \%$ for the 1985 image and $82 \%$ for the 2011 image).

In anniversaries where availability of ancillary data about distribution of land-cover types is scarce, Google Earth can be used as a substitute as in this paper. Here, more than 200 sample points across the different land cover types were captured and used to refine and assess the accuracy of the outputs previously generated from unsupervised classification. As inferred from the discussion, the performance of the data captured from Google Earth greatly depends on the age of the background image. Indeed, the extent to which these captured data matched the imaged realities in respective anniversaries is seen to be highly associated to the reflected accuracy measure of respective anniversaries. Given that the background image in Google Earth over the study area was acquired in 2000 , it is expected that land cover classification outputs of 2000, 2005 and 2010 had fairly higher level of overall accuracy $(64 \%, 79 \%$ and $68 \%$ respectively) and Kappa statistic $(0.47,0.69$ and 0.53 respectively) compared to similar measures in 1985 and 1995 classification outputs.

Post-classification change detection and trend analysis involved three land cover classes namely tea plantation, forest/woodlot and annual crop fields (sometimes denoted as others). The three land uses/covers followed different and inconsistent temporal land use dynamics across the change-analysis periods, while experiencing different intensity of dynamics. Apart from the 1995-2000 period where the extent of tea plantation apparently decreased by $7 \%$ (1,482 ha), the other change analysis periods showed an increase; $2 \%$ (370 ha) in 1985-1995 period, 11\% $(2,164 \mathrm{ha})$ in $2000-2005$ period and $11 \%(2,452 \mathrm{ha})$ in 2005-2010/11 periods. With regard to forest/woodlot cover, the period between 1985 and 1995 was apparently occasioned by 9\% (1,236 ha) loss of forest cover, 1995-2000 and 2000-2005 change analysis periods were typified by increase of the extent of forest/woodlot cover by about $21 \%$ (2,513 ha) and 9\% (1,376 ha) respectively while the period between 2005 and 2010/11 reflected an accelerated loss of forest/woodlot cover by about $40 \%$ (6,342 ha). As for the annual crop fields (or others), the period between 1985 and 1995, experienced a 3\% (678 ha) slight increase in the extent of annual crop fields (others), later evolving a negative trend in the subsequent change analysis periods, i.e. a decline by 5\% (1,050 ha) between 1995 and 2000 and $19 \%$ (3,607 ha) between 2000 and 2005 before showing a slight increase (1\%, 229 ha) in the 2005-2010/11 period. These dynamics are associated with the large-scale landscape transformation that occurred following construction of Ndakaini dam, transitional policies of the Kenyan government regarding utilizations of forest products especially from gazetted forest and the land cover change associated with dynamics of establishing and harvesting of woodlots to feed the tea factories. These findings are highly relevant for land use planning and natural resources management in Ndakaini area where the main concern is about sustainable future supply of quality water from Ndakaini dam against the background of continuing land-cover dynamics associated with the said driving factors that bears heavily on the management of the catchment.

The study has demonstrated the utility of skilled implementation of gap filling and mosaicing techniques and post-classification change detection method to circumvent the cloud and cloud-shadow problem often common in tropical humid highlands thereby enhancing the application of remote sensing to address deficit of quantitative information about land-cover dynamics.

\section{References}

A. Singh (1989). Digital change detection techniques using remotely-sensed data. International Journal of Remote Sensing 10: 989-1003.

1. Aplin, P. (2004). Remote sensing: land cover. Progress in Physical Geography 28 (2): 283-293.

2. Carlos Souza Jr., Laurel Firestone, Luciano Moreira Silva, Dar Roberts (2003). Mapping forest degradation in Eastern Amazon from SPOT 4 through spectral mixture models. Remote Sensing of Environment 87: 494506.

3. Christian Tottrup (2007). Forest and Land Cover Mapping in a Tropical Highland Region. Photogrammetric Engineering \& Remote Sensing 73 (9): 1057-1065.

4. D. Lu, P. Mausel, E. Brondizio, and E. Moran (2004). Change detection techniques. International Journal of Remote Sensing 25: 2365-2407.

5. Hakan Alphan, Hakan Doygun and Yuksel I. Unlukaplan (2009). Post-classification comparison of land cover using multi-temporal Landsat and ASTER imagery: the case of Kahramanmaras, Turkey. Environmental Monitoring \& Assessment 151: 327-336.

6. J. -F. Mas (1999). Monitoring land-cover changes: a comparison of change detection techniques. International Journal of Remote Sensing 20 (1): 139-152.

7. MoA, Gatanga District, (2010). Farm Management Guidelines -Gatanga District. Ministry of Agriculture, Gatanga District. 
8. P. Coppin, I. Jonckheere, K. Nackaerts, B. Muys, and E. Lambin (2004). Digital change detection methods in ecosystem monitoring: a review. International Journal of Remote Sensing 25: 1565-1596.

9. Qingmin Meng, Bruce E. Borders, Chris J. Cieszewski and Marguerite Madden (2009) Closest spectral fit for removing clouds and cloud shadows. Photogrammetric Engineering \& Remote Sensing 75 (5): 569-576.

10. Sobrino, J.A., Jimnez-Munoz \& Paolini, L. (2004). Land surface temperature retrieval from Landsat TM5. Remote Sensing of Environment 90 (4):434-440.

11. Vemu Sreenivalulu and Pinnamaneni Udaya Bhaskar (2010). Change detection in land-use/land-cover using remote sensing and GIS techniques. International Journal of Engineering Science and Technology 2 (12): 7758-7762.

12. Wafam Nori, El Nour Elsiddig, Irmgard Niemeyer (2008). Detection of land cover changes using multitemporal satellite imagery. The International Archives of the Photogrammetry, Remote Sensing and Spatial Information Sciences XXXVII Part B7.

13. Weicheng Wu, Eddy De Pauw A simple algorithm to identify irrigated croplands by remote sensing. (Unpublished).

14. Yichun Xie, Zongyao and Mei Yu (2008). Remote sensing imagery in vegetation mapping; a review. Journal of Plant Ecology 1(1):9-23.

\section{Biography}

Joram K. Kagombe: The Author is a full member of Forest Society of Kenya and its Immediate past national chairman. He holds PhD in Environmental Science from Kenyatta University, Kenya; MSc Tropical Forestry and Management from Technical University of Dresden, Germany and BSc Forestry from Moi University, Kenya. He is a Chief Research Scientist in Kenya Forestry Research Institute and Deputy Director, Socioeconomic, Policy and Governance. His areas of specialization are Community participation in forestry, Natural resource management planning, Payment for ecosystem services, ecosystem service valuation and Research on policy and governance in forestry.

Stephen M. Kiama: The Author is a Research Scientist in Kenya Forestry Research Institute (www.kefri.org). His training background is in natural resource management and application of Remote Sensing and GIS. His research interest include quantification of above-ground carbon and water balance over wooded grasslands, focusing on integration of remote sensing technologies with process-based model. 